\title{
Ecologismo dos pobres, Colonialismo e Metabolismo Social
}

Entrevista com Professor Joan Martinez-Alier, realizada por Felipe Milanez', gentilmente cedida para o Grupo Temático Povos e Comunidades Tradicionais, Questão Agrária e Conflitos Socioambientais do IPDMS.

\section{INTRODUÇÃO}

Joan Martinez-Alier é um economista ecológico da Catalunha, professor emérito da Universidade Autônoma de Barcelona, ambientalista, anarquista, coordenador do projeto de mapeamento de justiça ambiental EJOLT (Environmental Justice Organisations, Liabilities and Trade) 2011-15 e do novo projeto EnvJustice, 2016-21, uma bolsa de 2 milhões de euros financiado pela União Europeia para o desenvolvimento de pesquisas sobre e com os movimentos por justiça ambiental. Editor e fundador da revista Ecología Política, autor de dezenas de artigos científicos e membro do conselho editorial de revistas internacionais de grande impacto como Ecological Economics, Journal of Agrarian Change, entre outras, ativista político e autor de inúmeros artigos na imprensa internacional, colunista no jornal mexicano La Jornada, e publicações de organizações de movimentos sociais, como La Décroissance. Ministra aulas em universidades na Europa, nos Estados Unidos, na FLACSO

1 Professor Dr. Felipe Milanez da Universidade Federal do Recôncavo da Bahia, European Network of Political Ecology (Entitle) e Carta Capital http://www.cartacapital.com.br/ colunistas/felipe-milanez.Livro mais recente: Memórias Sertanistas: Cem Anos de Indigenismo no Brasil. (SESC, 2015). *Transcrição realizada por Carla da Paixão F. de Miranda e Professor Assis da Costa Oliveira (UFPA). GT 04 do IPDMS coordenado pelo Professor Dr. Carlos Frederico Marés de Souza Filho (PUC/PR); Professora Dra. Mariana Trotta Dallalana Quintans (UFRJ); Professora Dra. Erika Macedo Moreira (UFG) e Professor Eduardo Fernandes de Araújo (UFPB). 
no Equador, no México, junto dos zapatistas, na Índia com ativistas indígenas em Odisha, foi professor visitante na Unicamp, é doutor honoris causa pela Universidad de Cordoba, na Argentina, e autor do influente livro "O Ecologismo dos Pobres" (Ed. Contexto, 2007).

Esta entrevista foi realizada em Lisboa durante o evento organizado pelo Centro de Estudos Sociais (CES) Ecologia Política: teoria, investigação, ação, em 25 de março de 2015, para o lançamento do mapa de conflitos ambientais em Portugal. Martinez-Alier foi co-orientador de Felipe Milanez, autor da entrevista, no âmbito do projeto Entitle - European Netowork of Political Ecology, projeto de pesquisa em ecologia política financiado pela União Europeia.

A reflexão que segue é não apenas uma discussão sobre elaborações teóricas, conceituais e de luta de Martinez-Alier, pensadas no contexto brasileiro, o qual ele conhece desde os tempos em que trabalhou no Brasil, como professor visitante na Unicamp, durante os piores anos de chumbo da ditadura, sob o comando do general Emílio Garrastazu Médici, como pensamentos sobre a possibilidade de construção de alternativas, na América Latina, fora da dinâmica do colonialismo interno, imperialismo internacional, e o extrativismo massivo e predatório dos recursos naturais para exportação.

IPDMS: O que significa o "ecologismo dos pobres", e qual a razão de usar a palavra "pobre"?

Joan Martinez-Alier:A palavra pobre, para algumas pessoas, soa um pouco depreciativa. Na América Latina muitas vezes me sugerem não usar um ecologismo dos "pobres", mas dizer ecologismo dos "empobrecidos". Eu concordo, acho que é verdade. Porque o conceito também fala de indígenas, é o ecologismo dos pobres e indígenas, e os indígenas não são pobres, estão sendo empobrecidos. Também é possível falar da ecologia dos "despossuídos", há pessoas que usam o conceito nesse sentido. No entanto, por outro lado, eu acho que ecologismo dos empobrecidos, seja em português ou em espanhol, soa muito mais preciso, mas o ecologismo dos pobres tem mais força retórica. Um argumento a favor de ecologismo dos pobres é que a gente 
pobre muitas vezes se identifica como pobre. Nesse sentido, eu me lembro de quando eu trabalhava na Espanha, nos anos 60, na Andaluzia, e a pessoas falavam muito de "nós os pobres" e "eles os ricos", referindo aos senhores, os proprietários agrários. Este é inclusive o título de um capítulo da minha tese de doutorado, nosotros, los pobres ("nós, os pobres"). Há também um livro publicado na África do Sul cujo título é We are the poors ("Nós somos os pobres"), de autoria de Ashwin Desai, escritor de Durban. Também no México há filmes que utilizam a referência de nosotros, los pobres. Não sei em português como essa referência funciona, mas eu creio também que a gente pobre no Brasil se chama "nós, os pobres", como uma reivindicação social, como uma categoria social. Dizem "somos os pobres" porque têm os ricos, e isso funciona como uma reivindicação política. Portanto, eu creio que se pode falar ecologismo dos pobres, o que significa que os pobres, mesmo quando não se qualificam de ambientalista ou de ecologistas na prática, são muitas vezes ecologistas e ambientalistas que resistem contra as invasões de mineradoras, de petroleiras, de fazendas de palma ou de eucalipto, porque necessitam da natureza para viver, como um direito a todas as pessoas. Os ricos consomem mais a natureza do que os pobres. Os pobres conhecem os lugares, os territórios, conhecem de forma bastante direta a natureza. E isso também ocorre nas situações urbanas, onde muitas vezes os lixões, as incineradoras vão para bairros pobres, porque não vão por um lixão no bairro do Morumbi, em São Paulo, vão por na favela. Então a gente pobre protesta contra a má qualidade do ar, contra asma infantil.

\section{IPDMS: O ecologismo dos pobres é a luta pela justiça ambiental?}

Joan Martinez-Alier: O ecologismo dos pobres é parte do movimento global de justiça ambiental.

IPDMS: Há um tom provocativo no conceito, em referência ao ecologismo dos ricos?

Joan Martinez-Alier: Na origem disso há uma discussão dos anos 80 e 90, quando alguns cientistas políticos, como Ronald Inglehart, 
falavam que o ecologismo era uma novidade pós-1968, pós-materialistas. Eu acho que isso é muito errado porque o ecologismo, na Europa, mesmo nasce pelo movimento anti-nuclear, e, portanto, não é pós-materialista, mas preocupado com a radiaçãonuclear, que é invisível, mas é muito real e material, a radiação nuclear. Mas se dizia que era como um "novo" movimento social, como o feminismo, como a luta pelos direitos humanos, e que era algo de rico, de quem já tem um automóvel ou dois na garagem, então pode se preocupar com as baleias, se torna sócio do Greenpeace. E isto existe, este ecologismo de classe média, ambientalismos da classe média. Mas existe também,e é muito mais forte, o ecologismo dos pobres, em todas partes do mundo. Nos anos 80 havia como exemplo emblemático o Chico Mendes no Acre, no Brasil, assim como, um pouco mais tarde, nos anos 90, Ken Saro-Wiwa, em território Ogoni, no delta da Nigéria, que foi assassinado pelo Estado, com outros companheiros seus Ogoni, que com ele se puseram contra a companhia de petróleo Shell e contra a ditadura militar. Isto não é pós-materialistas, isto é uma luta muito materialista contra a contaminação do petróleo, contra o gás, porque a Shell queima o gás que sai com o petróleo, e este gás não vai para exportação. A queima do gás se dá a 40 metros de onde está morando essa gente que protestava contra essa exploração. Isso é o ecologismo popular, como também poderia se chamar, "ecologismo do povo",que não é dos pobres, mas ecologismo popular.Meu livro de 1992 em espanhol (Icaria, Barcelona) se chama "Da economia ecológica ao ecologismo popular", do discurso das "externalidades" não valoradas pelo mercado a investigação participativa nos movimentos sociais ecologistas. Foi publicado no Brasil pela FURB (Blumenau) em 1998. Ecologismo ou ambientalismo popular.

IPDMS: Como o senhor analisa a questão da consciência, da auto-reflexão dessa gente ambientalista popular?

Joan Alier: A consciência social nasce de situações reais e alguma coisa a mais. Por exemplo, para ser feminista, é mais frequente ser mulher que homem, e aí movimento social por liberdade sexual, que mais frequentemente parte de mulheres e de gays e $\mathrm{LGBT}^{*}$, que não 
de homens machistas, mas vem daqueles que sofrem a violência do machismo. E é o mesmo que acontece com os trabalhadores: alguém pode ser trabalhador e não ter muita consciência da classe trabalhadora, inclusive pode haver rico com consciência trabalhadora, o que é uma exceção... Nesse sentido, um rico que queira ser pobre é pouco frequente, e um pobre que queria se rico é mais frequente, mas em geral é a gente pobre que tem consciênciatrabalhadora. Quem tem também mais consciência ecologista? Quando olhamos um período mais amplo da história, a palavra ecologia não era usada politicamente até os anos de 1960 ou 1970, e mesmo assim facilita a compreensão de muitos conflitos sociais que eram ambientais e ecológicos, por exemplo, em Cubatão, em São Paulo, nos anos 60 e 70, quando aconteceu a contaminação química. Nos anos 70, as pessoas protestavam, a luta não eraexplicitamentedos ambientalistas e ecologistas porque não se usavam ainda essas palavras. Eram, simplesmente,habitantes de bairros pobres, mas era um sentido próximo da ideia desse termo. Se observarmos a Península Ibérica,nas lutas contra a Rio Tinto e a contaminação pelo dióxido de enxofre,pelo minério de cobre e fundição de cobre, isso aconteceu em 1888 na Andaluzia. Foi nessa data que houve um grande massacre de pessoas que protestavam, muitos trabalhadores anarco-sindicalistas e camponeses da região, todos juntos, que naquela época não podiam dizer "somos ambientalistas e ecologistas", porque não se usava esses termos. Mas na prática eram isso. Na história há muitos exemplos do ecologismo popular. Agora, hoje em dia, é mais frequente que se diga "somos ambientalistas", mas até hoje também depende, não é? Por exemplo, em Honduras, que hoje é uma ditadura, e muitas pessoas são mortas em Hondurasporque protestam contra as empresas de mineração. Eu imagino que com uma situação de repressão, se alguém vai lá e pergunta para essa gente por que protestam, por que são comunistas? Podem dizer que "não, comunista não sou, porque sou ecologista". Mas isso provoca ainda mais violência do Estado? 
IPDMS: A perspectiva hegemônica de que o centro industrial e financeiro está no Norte Globale que as regiões distantes seriam as "fronteiras", pode na verdade ser invertida no sentido de que são, na verdade, os centros da luta do capitalismo?

Joan Martinez-Alier: O capitalismo industrial, ou qualquer sistema industrial, funciona usando energia de combustíveis fósseis, metais e também biomassa para a indústria, para o biodiesel ou para fazer papel. As fronteiras da extração dos recursos não estão no centro do mundo, si chamamos centro a Nova lorque, ou Shangai, ou Londres, porque hoje não é como no passado quando a periferia iria exportar um pouco de ouro ou de prata, como na época de Pizarro ou Herman Cortez, mas trata-se de centenas de milhares de toneladas. Carajás e Minas Gerais, a Samarco, é periferia ou o centro do mundo? O delta do rio Niger, com a extração de dois milhões de barris de petróleo por dia, e periferia ou centro do mundo? São periferias no sentido que o fluxo de energia e de matérias segue para o centro, e os custos sociais e ambientais ficam nessa periferia. E agora, importa-se muitíssimo mais em toneladas do que nunca antes na história. E onde está esse petróleo que alimenta a indústria? Em parte está na Amazônia do Peru, do Equador e no Brasil também tem um pouco, no pré-sal. E onde está o gás de xisto? Está em muitos locais, porém está em maior concentração na Patagônia, por exemplo. E nessa perspectiva, visto da Europa, a Patagônia é o fim do mundo. Porém, visto metabolicamente, esta periferia é justamente o centro do mundo, porque é lá onde vão encontrar gás para explorar. Sem periferia no há centro.

IPDMS: Nesse sentido, Carajás, no Pará, é um dos principais centros do mundo de extração de minério de ferro e, também,de conflito social?

Joan Martinez-Alier: Sim. Mas vale a pena distinguir entre o que são preciosidades, os metais preciosos, por exemplo, como diamantes, que são muitos utilizados para a economia capitalista, ou seja, são muito importantes e tem um grande valor econômico grande, mas não são matérias primas muito importantes. Talvez até podem ser pequenos e 
muito importantes, como o Coltan ou a prata. Mas essas preciosidadestêm muito preço, só que elas não tem grande importância metabólica, diferentemente do que foi o nitrato de sódio para o Chile, a borracha da Amazônia para a indústria pneumática, que eram matérias primas muito importantes, sem as quais não se poderia funcionar o sistema industrial. Matérias em que havia o deslocamentoda extração. Por exemplo, a Inglaterra, a Alemanha e a França produziam oseu próprio carvão até 1914. Já depois da primeira Guerra Mundial começa a economia do petróleo; a indústria nuclear francesa não funciona sem o urânio do Niger, e o urânio da Niger está no centro geopolítico do mundo porque ali existe de tudo: hoje há a Al-Qaeda, existe a empresa Areva, existe o exército francês que está ali para impor a paz, aquela paz colonial, e agora este urânio ficou menos importante depois do desastre de Fukushima, no Japão. Mas onde há urânio, ali é o centro do mundo.

\section{IPDMS: Esta é uma explicação econômica, e como funciona a dominação do colonialismo nesse sistema?}

Joan Martinez-Alier: São situações econômicas, mas principalmente ecológicas e metabólicas. Eu creio que esta é a verdadeira economia. A economia não é só o dinheiro e o mercado, mas também a parte material. Porém os economistas muitas vezes não sabem da parte material, pensam que se um produto é mais caro, ele será substituído por outro. Pode até ser verdade, produto por produto. Mas um produto não vai poder substituir a quantidade de energia, não vai poder substituir nada por água, por exemplo, para a indústria da hidroeletricidade, com o que pode substituir a água? A quantidade é tão grande que não pode ser substituída. Tudo isso fomenta um certo coIonialismo e um imperialismo. É muito interessante o que vai se passar com China, que está cada vez mais presente em conflitos extrativos na África e na América Latina. Creio que não é por vontade imperialista que vão impor um domínio político, mas pouco a pouco vão ter que exercer esse domínio. Por exemplo, no Equador se instalou uma indústria de petróleo chinesa onde não se metem as industrias de petróleo europeiasporque é uma área muita conflitiva na Amazônia. Mas se colocam empresas chinesas. No território Shuar no sudeste 
do Equador, que são indígenas que vivem na fronteira, está uma empresa chinesa para tirar cobre... Além disso, eles dão crédito ou então compram a matéria-prima de maneira antecipada. Isto é, o Equador deve entre 6 e 8 bilhões de dólaresa China, o que representa cerca de 500 dolares por cada equatoriano, e esse valor vai subindo. $\mathrm{O}$ que a China vai fazer se o Equador não pagar essa dívida? Vai enviar uma tropa, o exército, vão falar com o Fundo Monetário Internacional, vão enviar um porta-aviões chinês para cobrar a dívida? Isto é algo que iremos verificar no futuro, em vinte ou trinta anos, como a China atua como uma potencia imperialista. Então esta é interpretação de como o colonialismo continua operando. Eu acredito que é verdade, e ocorre em muitas dimensões: econômica,ecológica, geopolítica.

\section{IPDMS: Uma forma de colonialidade?}

Joan Martinez-Alier: Sim, mas também não é apenas colonialismo exterior, também ocorre muitasvezes como um colonialismo interno. Assim se dizia no México, a teoria do colonialismo interno de Stavenhagen, de González Casanova. Porque no Brasil quem se comporta de forma colonial com os povos indígenas, muitas vezes são brasileiros porque tem interesses extrativos de grilagem de terra para a soja, para a carne, para a grande empresa JBS-Friboi, que é a maior empresa de produção de carne do mundo, e com muita terra na Amazônia. Este é um colonialismo internototalmente brasileiromotivado em parte pela exportação. São brasileiros que colonializam ou recolonializam os povos indígenas, que na verdade os destroem. Eu creio que seja verdade o que dizem Anibal Quijano, Walter Mignolo ou Arturo Escobar, que o tema não é só ecológico, metabólico, mas é cultural também: o colonialismo interno apoiado pelo imperialismo exterior.

IPDMS: Como mudar essa colonialidade isso sem mudar o capitalismo, oucomo mudar o capitalismo ou, ainda, acabar com o capitalismo?

Joan Martinez-Alier: Tenho uma receita que é muito fácil, decrescimento no Norte, prosperidade sem crescimento no Norte, como fala 
Tim Jackson, ou Herman Daly, que há quarenta anos fala de uma steady state economy (economia do estado estacionário). Existem pequenas diferenças entre estes conceitos, mas é o mesmo significado, que já não devemos crescer mais no Norte ante as mudanças climáticas e porque também estamos provocando todo este desastre no Sul. Não é só Europa, mas também o Japão, a parte industrial de China, os Estados Unidos, São Paulo, então se precisadecrescimento no Norte e de justiça ambiental em todo o mundo, ou justiça socioambiental. Estes movimentos de ecologismo popular e de resistência também tem vários outros nomes e forma um grande movimento global de justiça ambiental, um movimento político que não tem comitê central. Eé melhor que não tenha, porqueassim há muitos grupos que se ajudam mutuamente uns aos outros, que se comunicam e que possuem estratégias. Claro que o tema da mudança climática une a todos, também a perda da biodiversidade e os protestos pela justiça ambiental. A justiça ambiental não é um tema especializado, é um tema central.

\section{IPDMS: A questão da justiça ambiental é uma luta por distribui- ção, ou a justiça é uma luta pela igualdade?}

Joan Martinez-Alier: Já faz anos, vários teóricos dizem que a justiça tem umaspecto de distribuição, isto é: que não te tirema água, a terra, a vida, digamos,se chamamos de distribuição um "não quero que me matem e quero continuar tendo minha subsistência", mas também justiça é o aspecto do reconhecimento, que na América Latina se fala em relação à Convenção 169 da OIT (Organização Internacional do Trabalho), que se fala muito, mas na prática não se permite efetivar. Na Guatemala têm ocorrido muitas tentativas de aplicação da 169para a proteção de direitos dos povos indígenas, mas os governos não reconhecem. De alguma maneira, os movimentosprocuram o reconhecimento, o aplicam com referendos locais ou mesmo com ação direta, como por exemplo parar projetos. Acontece queo exército ou a polícia, matam. Para melhorar a distribuição ecológica é precisoo reconhecimento, respeito. A justiça é também a possibilidade de participarfalando o seu próprio idioma,ou seja, sem que seja tirada a capacidade de conversar o seu próprio idioma, inclusive de valoração, e de ter a sua 
terra, de ter água e de ter comida. É a capacidade mínima. Se te tiram o idioma, a água, a terra e a comida, te destroem.

\section{IPDMS: Estes conflitos são provocados pelo aumento do me- tabolismo?}

Joan Martinez-Alier: a luta por energia e por materiais provoca a destruição de muitos ecossistemase de muita gente. Também de outras espécies, dos tigres e de muitas outras formas dabiodiversidadee a diversidade humana são destruídas. Essaenergia do metabolismo industrial não se pode reciclar: o petróleo, o gás,o carvão, se queimas uma vez, se queimou para sempre. O carvão vegetal para a indústria do ferro-gusa, ainda que voltem a crescer as árvores, mas quanto foi queimado não vai voltar a crescer, não é? Isso depende da árvore: se é eucalipto, leva 15 anos, se é, como era Argentina, o quebracho (tipo de árvore) que o cortavam para a indústria têxtil nos anos 20 e 30, o quebracho crescia muito devagar. O metabolismo da economia é tal que não permite a renovação. Porque aquelas espécies que produzem a fotossíntese usam a energia solar e fazem nascer a vida do sol, da água, do carbono. A diferença entre o que é renovável e o que não é renovável se está acabando, inclusive porque o renovável está sendo tratado como não renovável. O metabolismo é tal que ao final produz resíduos. Mas agoratemos a União Europeia, onde a política oficial é a economia circular, assim como a China também fala que a economia será circular. Mas isto é uma utopia, uma mentira, em que todos os resíduos serão de volta matéria-prima. Primeiro, os que não são renováveis, os impossíveis de serem renováveis, como o petróleo o carvão que estão sumindo para sempre. Odióxido de carbono produzido pela queima do petróleo não vai poder ser reciclado através de uma nova vegetação, ao menos nesta quantidade que estamos produzindo tão grande,em que estamos mudando o clima. 


\section{IPDMS: E o que é que move o metabolismo? O que faz acelerar o metabolismo?}

Joan Martinez-Alier: Se poderia interpretar que um capitalismo sem crescimento é impossível, não? Porque um capitalismo sem crescimento não pode pagar osinteresses dos empréstimos dos bancos, os juros dos bancos,e todo o capitalismo historicamente sempretem passado por isso,pelos pagamentos de juros ou pelo pagamento dos benefícios das empresas que permitem acumulação, investir. Marx dizia isso, que a acumulação é o Deus e profeta do capitalismo. Eu creio que isto é verdade. Mas também, imagina um sistema que não fosse capitalista, que fosse stalinista ou socialista democrático, mas se fosse industrial seria muito parecido no que faz esse movimento metabólico, porque agora as toneladas não são poucas toneladas como do ouro de Ouro Preto. Agora são as milhões de toneladas de Carajás. Então, um sistema mundial socialista seria muito diferente? Bom, depende. Poderia ser um sistema comunitário sem crescimento, com uma distribuição melhor no mundo, com uma população mais ou menos estável, e mudança tecnológica com muito mais produção de energia solar. Porém, nesse momento, o único sistema que existe é o capitalista, capitalismo neoliberal ou capitalismo de Estado, como na China porque o Estado intervém muito, e é igualmente agressivo com o ambiente. $\mathrm{Na}$ América Latina, os governos nacionalistas-populares distribuem a renda melhor do que em Colômbia, isto é verdade, é um capitalismo rentista-distributivo ou, de outra maneira, compensador, um sistema de extrativismo compensador. Porém, esta palavra,"compensador", o que significa? Porque, por exemplo, com relação à Usina Hidrelétrica de Belo Monte, a compensação, às vezes, está em introduzir a valoração monetária de elementos que são incomensuráveis. Isso acontece em muitos lugares do Sul, como na Índia também. Se desaparece um grupo tribal, com seu idioma tão antigo, isto como se compensa? Compensar a perda de um idioma? Compensar um genocídio? 